\title{
Study on Fluorescent Powder Using in Packaging of LED COB for Marine Fishing
}

\author{
Zhengye Xiong ${ }^{1}$, Pinwang Lin² $^{2}$ Yongqiang $\mathrm{Li}^{1 *}$, Yongqi Liang ${ }^{1}$, \\ Qingxiang Chen ${ }^{3}$, Wenqing Shi ${ }^{1}$
}

${ }^{1}$ School of Electronic and Information Engineering, Guangdong Ocean University, Zhanjiang, China, 524088; ${ }^{2}$ Foshan Blue Rocket Electronics comply, LTD, Foshan, China, 528051; ${ }^{3}$ School of Oceanology and Meteorology, Guangdong Ocean University, Zhanjiang, China, 524088

* Corresponding author, E-mail: lyq196399@163.com

Key words: Lutetium Aluminum Garnet, Phosphor, Marine fishing, Light Emitting Diode (LED)

Abstract: In recent decades, developing new energy saving light source is an important research in light-fishing industry. With the development of semiconductor technology, people want to replace traditional metal halide lamp with more energy-saving LED lamp. In this paper, Two phosphors, LuAG $\left(\mathrm{Lu}_{2.945} \mathrm{Al}_{5} \mathrm{O}_{12}: 0.055 \mathrm{Ce}\right)$ and $\mathrm{YGAG}\left(\mathrm{Y}_{2.96} \mathrm{Al}_{3.4} \mathrm{Ga}_{1.6} \mathrm{O}_{12}: 0.04 \mathrm{Ce}\right)$, were developed and compared with commercial phosphors GM537H7D2 (produced by Jiangsu Bree Optronics Co., Ltd). We packaged $60 \mathrm{~W}$ blue LED COBs (emission wavelength is about $450 \mathrm{~nm}$ ) with these phosphors and found out that when the ratio of glue to phosphor LuAG is 1:0.10, the maximum luminous efficiency can be obtained to reach $125 \mathrm{Lm} / \mathrm{W}$, when the ratio of glue to phosphor YGaAG is 1:0.10, the maximum luminous efficiency can be obtained to reach $112 \mathrm{Lm} / \mathrm{W}$. Compared with this, the highest luminous efficiency with commercial fluorescent powder GM537H7D2 is 120Lm/W. Because the maximal emission of LuAG phosphor is about $520 \mathrm{~nm}$, which is very effective in attracting squid and many kinds of marine fish, and the efficiency of fluorescence conversion of the phosphor is very high, the fluorescent powder LuAG is very suitable for the package of LED COB using in LED fishing lamps.

Many species of fishes, such as squid, mackerel, sardines and bream have phototaxis ${ }^{[1,2]}$. People developed a set of fishing lamp system to improve the efficiency of fishery. At present, the popular marine fishing lamp is metal halide lamp. Many fishes are attractive by blue and green light ${ }^{[2]}$. Most of the light emission from metal halide lamp is not in the effective band in which light is attractive to most fishes. Ineffective light wastes a lot of electricity and causes light pollution. The strong ultraviolet light emitted from metal halogen lamp may even burn the skin of fishermen. People are looking for lighting sources from which the light emission is almost in the effective band, and the LED lamp is undoubtedly the best choice. More and more countries are carrying out researches in this field, and have made some progress ${ }^{[3-5]}$, but these studies are usually confined to simple blue light LEDs or white light LEDs. The light emission from blue LED is mainly in the band of 430nm-470nm ${ }^{[6]}$, and the effect of attracting fish is not very good ${ }^{[7]}$, therefore, we need to add some green phosphor into blue LED to turn some blue light into green light and the emission from the lamp will be more attractive to most fishes.

We have developed two kinds of garnet structural phosphors, LuAG:Ce ( $\left.\mathrm{Lu}_{2.945} \mathrm{Al}_{5} \mathrm{O}_{12}: 0.055 \mathrm{Ce}\right)$ and YGaAG:Ce $\left(\mathrm{Y}_{2.96} \mathrm{Al}_{3.4} \mathrm{Ga}_{1.6} \mathrm{O}_{12}: 0.04 \mathrm{Ce}\right)$. As a reference, we chose a commercial fluorescent powder, fluorescent powder GM537H7D2 produced by Jiangsu Bree Optronics Co., Ltd. The three kinds of phosphors are used to encapsulate LED COB with the same process. 


\section{Experiment}

The two samples were prepared by the traditional solid state reaction method. First, the analytically pure $\mathrm{Lu}_{2} \mathrm{O}_{3}, \mathrm{Y}_{2} \mathrm{O}_{3}, \mathrm{Ga}_{2} \mathrm{O}_{3}, \mathrm{Al}_{2} \mathrm{O}_{3}$ and $\mathrm{CeO}_{2}$ were mixed into the blender according to the ratio, so that the raw materials were fully and evenly mixed. After dry pressing (adding a small amount of alcohol) into large blocks, they were placed in a corundum crucible and heated to $1600^{\circ} \mathrm{C}$ in an electric furnace, and then kept at that high temperature for 5 hours. During the firing process, shielding gas of $5 \% \mathrm{H}_{2}$ and $95 \% \mathrm{~N}_{2}$ was flowing into the furnace chamber until cooling. The agglomerates were put out from the furnace and be milled into fine powder. $\mathrm{X}$ ray diffraction shows that the fine powder is in a garnet structure.

The Hitachi F-4500 fluorescence spectrometer was used to test the performance of the phosphor, and it was confirmed that three kinds of phosphors have strong stimulated luminescence in 440nm $460 \mathrm{~nm}$. The three phosphors were mixed into the transparent packaging silica gel at different ratios, and the mass ratio of silica gel to phosphor was 1:0.04, 1:0.06, 1:0.08 and 1:0.10 respectively. The blue light LED COB of $60 \mathrm{~W}$ is encapsulated with silica gel and the main wavelength of the blue light COB is about $450 \mathrm{~nm}$, the luminous surface is round with the diameter of $24 \mathrm{~mm}$, thickness of about $0.5 \mathrm{~mm}$.

The spectral analysis system EverFine PMS-80 was used to measure the luminescence parameters of the COB. Power supply of the COB is with constant voltage of $40 \mathrm{~V}$ and constant circulation of $1500 \mathrm{~mA}$. The substrate temperature maintains about $25^{\circ} \mathrm{C}$. The parameters including luminescence spectrum, total luminance, and total radiant flux are measured.

\section{Analysis and discussion}

\section{fluorescence spectrum}

The three samples are all garnet structure and the shapes of the excitation and emission spectra are similar, but the wavelengths are slightly different. The excitation and emission spectra of LuAG:Ce $\left(\mathrm{Lu}_{2.945} \mathrm{Al}_{5} \mathrm{O}_{12}: 0.055 \mathrm{Ce}\right)$ phosphor are shown in Figure 1.
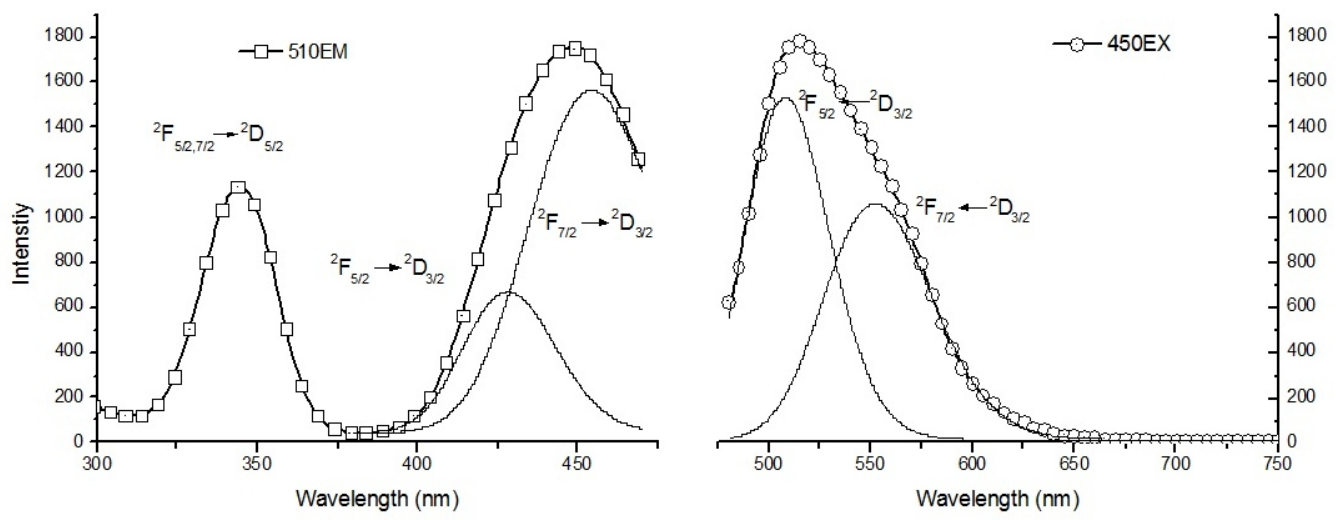

Fig. 1. Fluorescence spectrum of phosphor LuAG:Ce. Spectra of the other two phosphors are similar to that of LuAG:Ce, and the peak-wavelengths are slightly different.

It can be seen from Fig. 1 that the phosphor can be excited not only by ultraviolet light near $340 \mathrm{~nm}$ (corresponding to the transition ${ }^{2} \mathrm{~F}$ to ${ }^{2} \mathrm{D}_{5 / 2}$ of $\mathrm{Ce}^{3+}$ ions), and also excited by blue light near $450 \mathrm{~nm}$ (corresponding to transitions ${ }^{2} \mathrm{~F}$ to ${ }^{2} \mathrm{D}_{3 / 2}$ of $\mathrm{Ce}^{3+}$ ions). LuAG:Ce can be excited easily by the blue light emission near 450nm from the LED chip and turn it to green light near the 520nm (corresponding to the transition ${ }^{2} \mathrm{D}_{3 / 2}$ to ${ }^{2} \mathrm{~F}_{5 / 2,7 / 2}$ of $\mathrm{Ce}^{3+}$ ions). The fluorescence spectra of the other two samples (YGaAG and GM537H7D2) are similar to that of LuAG:Ce, but the wavelength 
moves slightly to a little longer.

\section{Emission spectra of $\mathrm{COB}$}

The encapsulated COBs are fixed on a refrigerator to keep the substrate at nearly a constant temperature, power supply of the COBs are with constant voltage of $40 \mathrm{~V}$ and constant circulation of $1500 \mathrm{~mA}$ and the emission spectra are shown in figures 2 and 3.

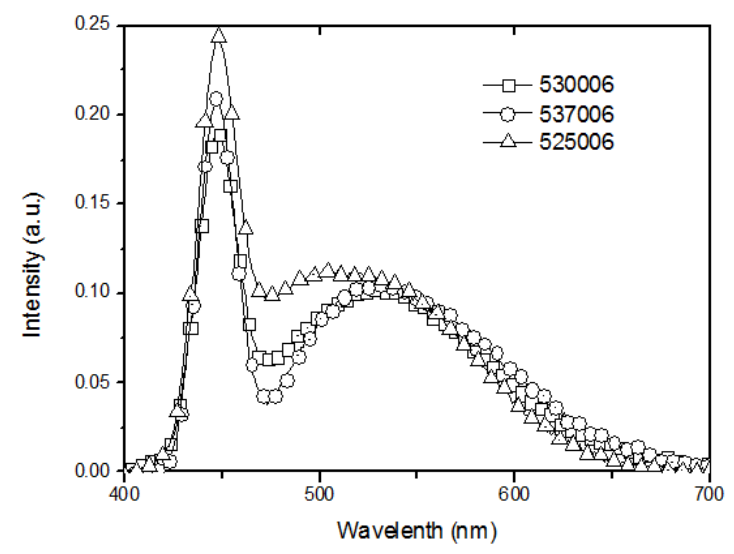

Fig. 2. Emission spectra of COBs encapsulated with three different phosphors of same concentration. 525006 indicates LuAG:Ce, 530006 indicates YGaAG:Ce, 537006 indicates GM537H7D2, and the ratio of glue to phosphors is 1:0.06.

It can be seen from Fig. 2 that the emission at the wavelength longer than 550nm from the COB with the commercial phosphor is the strongest and that with the LuAG:Ce phosphor is the weakest. However, the emission at the wavelength shorter than $550 \mathrm{~nm}$ from the COB with phosphor YGaAG:Ce package is significantly higher than that of the other two.

The emission spectra of COBs encapsulated with three kinds of phosphors with different concentrations are shown in Fig. 3, and the mass proportions of the transparent silica to fluorescent powder are listed too. Diagram A is corresponding LuAG:Ce phosphors, diagram B corresponding to YGaAG:Ce phosphor and diagram C corresponding commercial phosphor GM537H7D2.
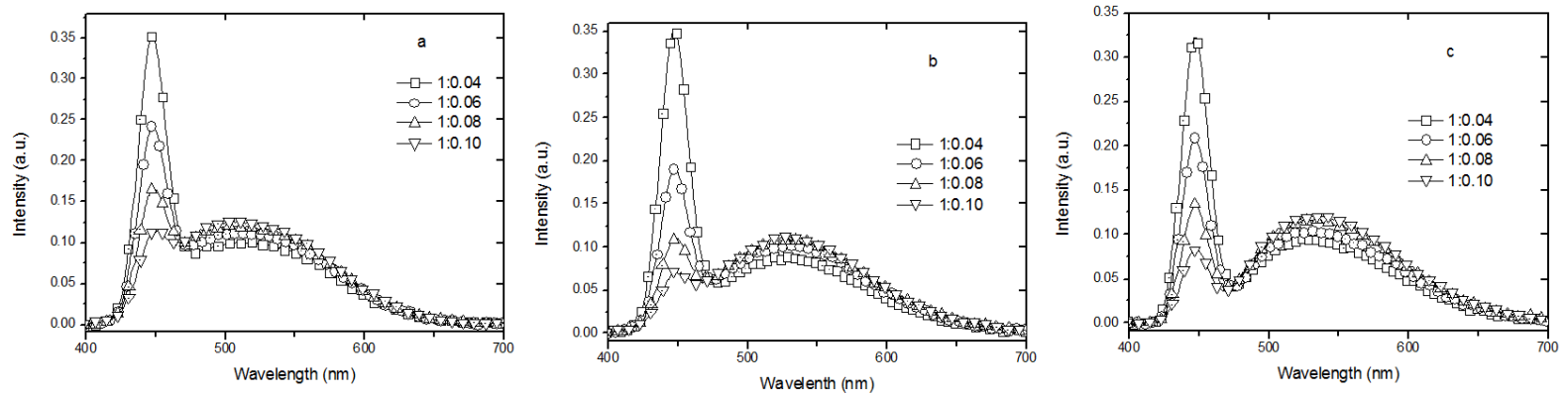

Fig. 3. Emission spectra of COBs encapsulated with phosphors of different concentrations. The ratios of glue to phosphor are listed.

It can be seen from Fig. 3 that with the increase of the proportion of fluorescent phosphors, the intensity of green light emitting from phosphor increases, and the intensity of blue light emitted from LED chips is reduced. This is the basic principle of adjusting the color temperature of light source with LED packaging technology: increasing the proportion of phosphors, warming the color of light sources, decreasing the proportion of phosphors and cooling the color of light sources. In Fig. 3, the spectra of 1:0.10 and 1:0.08 almost coincide at wavelengths larger than 480nm band, indicating that when the concentration of phosphor reaches a certain level, increasing the proportion of phosphors will not enhance the emission of green light no longer, but only decreases blue light significantly. 
When the ratio of silica gel to LuAG:Ce phosphor is 1:0.10 (Fig. 3A), the emission of COB is mainly concentrated in the $430 \mathrm{~nm} \sim 570 \mathrm{~nm}$ band, and the central wavelength is about 500nm. The emission is in the band which can attract many marine fishes ${ }^{[2,3,13-15]}$.

\section{COB electro-optical conversion efficiency and lumen efficiency}

The spectral system EverFine PMS-80 not only gives the spectral curves, but also the luminous flux and radiation flux of the light source, as well as the color temperature and other parameters of color coordinates. Chromaticity is for human vision, the COB packaging in this paper is for marine fishing and is based on fish's vision, so we do not discuss COB chromaticity parameters. Because the electric power of input $\mathrm{COB}$ is $60 \mathrm{~W}$, the luminous efficiency and electro-optical conversion efficiency of light source can be calculated from luminous flux and radiation flux. 5 samples of each package are made at the same process. According to the results of 5 samples, the standard error of corresponding parameters can be obtained. The results of the corresponding parameters are shown in Table 1.

Table 1. Electro-optical conversion efficiency and lumen efficiency of COBs encapsulated with different phosphors

\begin{tabular}{cccccc}
\hline Phosphor & $\begin{array}{c}\text { Ratio of } \\
\text { glue to } \\
\text { phosphors }\end{array}$ & $\begin{array}{c}\text { Luminous } \\
\text { flux (Lm) }\end{array}$ & $\begin{array}{c}\text { Lumen } \\
\text { efficiency } \\
\text { (Lm/W) }\end{array}$ & $\begin{array}{c}\text { Flux of } \\
\text { radiation } \\
\text { (W) }\end{array}$ & $\begin{array}{c}\text { Electro-optical } \\
\text { conversion } \\
\text { efficiency }\end{array}$ \\
\hline \multirow{5}{*}{ LuAG:Ce } & $1: 0.04$ & $5417 \pm 32$ & $90.3 \pm 0.6$ & $21.26 \pm 0.14$ & $35.4 \pm 0.3 \%$ \\
& $1: 0.06$ & $6393 \pm 38$ & $106.6 \pm 0.7$ & $20.77 \pm 0.14$ & $34.6 \pm 0.3 \%$ \\
& $1: 0.08$ & $7056 \pm 42$ & $117.6 \pm 0.7$ & $20.27 \pm 0.14$ & $33.8 \pm 0.3 \%$ \\
& $1: 0.10$ & $7513 \pm 44$ & $125.2 \pm 0.8$ & $20.13 \pm 0.14$ & $33.6 \pm 0.3 \%$ \\
\hline YGaAG:Ce & $1: 0.04$ & $4718 \pm 42$ & $78.6 \pm 0.7$ & $20.33 \pm 0.15$ & $33.9 \pm 0.3 \%$ \\
& $1: 0.06$ & $5850 \pm 52$ & $97.5 \pm 0.9$ & $19.47 \pm 0.14$ & $32.5 \pm 0.3 \%$ \\
& $1: 0.08$ & $6433 \pm 57$ & $107.2 \pm 1.0$ & $19.03 \pm 0.14$ & $31.7 \pm 0.3 \%$ \\
GM537H7D2 & $1: 0.10$ & $6728 \pm 60$ & $112.1 \pm 1.0$ & $18.80 \pm 0.14$ & $31.3 \pm 0.3 \%$ \\
\hline & $1: 0.04$ & $5272 \pm 40$ & $87.9 \pm 0.7$ & $19.94 \pm 0.16$ & $33.2 \pm 0.3 \%$ \\
& $1: 0.06$ & $5954 \pm 45$ & $99.2 \pm 0.8$ & $19.57 \pm 0.15$ & $32.6 \pm 0.3 \%$ \\
& $1: 0.08$ & $6786 \pm 51$ & $113.1 \pm 0.9$ & $18.91 \pm 0.15$ & $31.5 \pm 0.3 \%$ \\
& $1: 0.10$ & $7162 \pm 54$ & $119.4 \pm 1.0$ & $18.65 \pm 0.15$ & $31.1 \pm 0.3 \%$ \\
\hline
\end{tabular}

As can be seen from Table 1, there is no significant difference between the electro-optic conversion efficiency of YGaAG:Ce (Lu2.945A15O12:0.055Ce) phosphor and that of commercial fluorescent powder (GM537HD2). It is determined by the manufacturer that the GM537HD2 phosphor is also a YGaAG:Ce phosphor, but the content of $\mathrm{Ga}$ is different from the YGaAG:Ce phosphor that we have developed. Compared with commercial fluorescent powder, the luminescence efficiency of the LED COB packaged with phosphor YGaAG:Ce is slightly lower than that of the LED COB with commercial phosphor, while the electro-optical conversion efficiency of the LED COB packaged with phosphor YGaAG:Ce is slightly higher. YGaAG:Ce phosphors convert blue light into green light near 530nm, and GM537HD2 phosphors convert blue light into green light near 537nm. Visual sensitivity of light at 530nm is lower than that of light near $537 \mathrm{~nm}$, while the photon energy near 530nm is slightly larger than the photon energy near $537 \mathrm{~nm}$. Therefore, if the quantum conversion efficiencies of two phosphors are similar, there would be lower luminescence efficiency and higher electro-optical conversion efficiency. That is to say, there is no significant difference in the quantum conversion efficiency between the YGaAG:Ce phosphor and the commercial YAG phosphor.

We can see from table 1 that the highest luminous efficiency of the COB packaged with phosphor LuAG:Ce is $125 \mathrm{Lm} / \mathrm{W}$, and the conversion efficiency of electro-optical conversion of the COBs is more than $33.5 \%$, which is significantly higher than that of the other two groups. This 
shows that the quantum conversion efficiency of LuAG:Ce phosphors is higher than that of the other two kinds of phosphors.

The COBs packaged with phosphor LuAG:Ce performance high electro-optical conversion efficiency and high lumen output, and the output light is the most effective to attract many kinds of marine animals. Therefore, LuAG:Ce phosphor is very suitable for the LED COB packaging using for marine fishing lamp.

\section{Conclusion}

In this paper, two kinds of green phosphors, $\mathrm{LuAG}: \mathrm{Ce}\left(\mathrm{Lu}_{2.945} \mathrm{Al}_{5} \mathrm{O}_{12}: 0.055 \mathrm{Ce}\right)$ and $\mathrm{YGaAG}: \mathrm{Ce}$ $\left(\mathrm{Y}_{2.96} \mathrm{Al}_{3.4} \mathrm{Ga}_{1.6} \mathrm{O}_{12}: 0.04 \mathrm{Ce}\right)$, have been developed and compared with the commercial fluorescent powder GM537H7D2 from Jiangsu Bree Optronics Co., Ltd. With the three kinds phosphors, 60W blue LED COBs (wavelength of light emission is 450nm from LED chips) are packaged, and the electro-optical performances are measured. We can get the following results:

1) When the proportion of silica gel to phosphor LuAG:Ce is 1:0.10, the luminous efficiency of $\mathrm{COB}$ is the highest, reaching $125 \mathrm{Lm} / \mathrm{W}$. At the same time, the electro-optic conversion efficiency of $\mathrm{COB}$ is up to $33.6 \%$. Compared with the commercial fluorescent powder, the COB packaged with phosphor GM537H7D2 can be as high as 120Lm/W.

2) The quantum conversion efficiency of LuAG:Ce phosphor is higher than that of the ordinary YAG phosphor.

3) LED COBs packaged with LuAG:Ce phosphor have a illustrious emission in the band of $430 \mathrm{~nm}$ 570nm, which is very attractive to squid and other marine economic animal. Therefore, it is believed that LuAG:Ce phosphor is very suitable for high-power LED COB packaging in marine fishing industry.

\section{Acknowledgment}

This work is supported by Science and Technology Planning Project of Guangdong Province (2015A020216020), Project of Zhanjiang City (2015A02020) and Qihang Planning Project of Guangdong Ocean University (qhjh2017kj16).

\section{References}

[1] T. C. M. Bakker, D. Mazzi, S. Zala: Ecology, Vol. 78(1997), p.1098

[2] D. He, J. Xiao, H. Luo: Journal of Xiamen University (in Chinese), 3(1979), p.99

[3] Y. Yukiko, M. Yoshiki, A. Toru: Fisheries Research, Vol. 113(2012), p.182

[4] Y. Matsushita, T. Azuno, Y. Yamashita: Fisheries Research, Vol. 125-126(2012), p.14

[5] Y. An, P. He, T. Arimoto: Fish Science, Vol. 83(2017), p.343

[6] S. Nakamura, T. Mukai, M. Senoh: Applied Physics Letters, Vol. 64(1994), p.1687

[7] Q. Chen, Z. Xiong, Z. Tan: South China Fisheries Science (in Chinese), Vol. 9 No.3 (2013), P.80

[8] K. Park, T. Kim, Y, Yu: Journal of Luminescence, Vol. 173(2016), p.159

[9] S. Fu, J. Tan, X. Bai: Optical Materials, Vol. 75(2018), p.619

[10] Z. Ge, D. Klotzkin: Journal of Luminescence, Vol. 181(2017), p.184

[11] L. Wang, M. Yin, C. Guo: Journal of Rare earths, Vol. 28(2010), p. 16.

[12] L. Chen, C. Lin, C. Yeh: Materials, Vol. 3(2010), p. 2172

[13] R.H. Douglas, J.C. Parttridge, N.J. Marshall: Progress in Retinal and Eye Research, Vol. 17(1998), P. 597

[14] P.C. Gehrke: J. Fish Biol., Vol. 44(1994), p. 741 
[15] J.S. Levine, E. F. Macnichol: Scientific American, Vol. 246(1982), p. 140 